\title{
DIMENSÕES PRAGMÁTICAS DA VARIEDADE ANGOLANA DO PORTUGUÊS
}

Kimavuidi Ferreira (UBI)

Paulo Osório (UBI)

Resumo: $O$ presente texto pretende fazer uma abordagem pragmáticosemântica do morfema gramatical só na Variedade Angolana do Português. A razão subjacente ao estudo do tema deve-se ao fato de o referido morfema assumir, naquela variedade africana do português, valores funcionais muito distintos dos que a gramática tradicional the atribui, como, por exemplo, o de fórmula de cortesia e de expressão intensificadora, fruto do contato entre a língua portuguesa e as línguas africanas faladas em Angola.

Palavras-chave: Variedade Angolana do Português; Cortesia; Atenuação; Intensificação; Morfema.

Abstract: The present paper intends to make a pragmatic-semantic approach of the grammatical morpheme só in the Angolan Portuguese variety. The reason underlying the study of this theme is due to the fact that the morpheme assumes, in African Portuguese variety, functional values very different from those attributed by traditional grammar, such as the formula of courtesy and intensifying expression, fruit of the contact between the Portuguese language and the African languages spoken in Angola.

Keywords: Angolan variety of Portuguese; Courtesy; Attenuation; Intensifies; Morpheme.

\section{INTRODUÇÃO}

As palavras, como se sabe, servem para nomear o mundo. Mas como as nomeações surgem, como se consolidam e de que forma os seus significados são reciclados para produzirem novos significados (quer por extensão, quer por restrição), depende muito do contexto social em que 
as mesmas são usadas. Assim, a 'plasticidade' ou extensão semântica constitui um campo dos estudos linguísticos que tem sido objeto de reflexão desde a Antiguidade. Por ser um assunto pertinente, a linguística contemporânea, através da Semântica e da Pragmática, tem-se dedicado cada vez mais ao estudo do significado, o qual, em termos pragmáticos, é feito relacionando-o com o falante, ao passo que em semântica o mesmo é definido como propriedade das expressões de uma determinada língua. O presente trabalho pretende fazer uma abordagem pragmático-semântica do morfema gramatical só na Variedade Angolana do Português (VAP). A razão subjacente ao estudo do tema deve-se ao fato de o referido morfema assumir, naquela variedade africana do português, valores funcionais muito distintos dos que a gramática tradicional Ihe atribui, como, por exemplo, o de fórmula de cortesia e de expressão intensificadora, fruto do contato entre a língua portuguesa e as línguas africanas faladas em Angola. É, portanto, com o objetivo de, por um lado, analisar o funcionamento do morfema só e, por outro, de contribuir para a divulgação das particularidades da Variedade Angolana do Português que a presente investigação foi concebida.

O enquadramento do nosso trabalho em combinação com a análise qualitativa permitiu-nos responder às perguntas 
porquê? e como? uma vez que, identificado o fenómeno, foi possível identificar também as razões por que o mesmo ocorre, isto é, as razões por que o morfema só é usado, na VAP, com outros valores pragmático-semânticos (destacando-se o valor de fórmula de cortesia), não ocorrentes no Português Europeu (PE). A análise do corpus permitiu, por outro lado, compreender de que forma e em que circunstâncias pragmáticas o fenómeno acontece.

\section{DIMENSÃO PRAGMÁTICA DO MORFEMA SÓ: APRESENTAÇÃO E ANÁLISE DO CORPUS}

O nosso corpus tem como base obras literárias de escritores angolanos: Luuanda (VIEIRA $\left.{ }^{1}, 2004\right)$, Manana (XITU², 1988), Velhas Estórias (VIEIRA, 2006) e Crónica de um Mujimbo $\left(R U I^{3}, 1991\right)$. A razão subjacente à escolha das referidas obras reside no fato de nelas figurarem manifestações discursivas que espelham vivamente as particularidades

\footnotetext{
1 A escrita de Luandino Vieira (pelo menos a da segunda fase em que a sua obra é dividida, fase inaugurada exatamente pela esrita de Luuanda) é conhecida pelo génio recriativo do escritor e pela disseminação de marcas de angolanização da língua portuguesa, subvertendo a norma comunicativa do português-padrão de Lisboa, adoptando gírias, neologizações, tipicismos e outros recursos, também sintáticos, orais e tradicionais africanos, para construir uma língua literária propícia ao imediato reconhecimento da sua diferença. (LARANJEIRA, 1995, p.121).

2 O estilo de Uanhenga Xitu, por sua vez, é caraterizado por um entrelaçamento fiel entre a ficção e a realidade, numa linguagem coloquial em que é notável a influência do Kimbundu sobre o Português. Aliás, quanto a isso, o próprio autor, quando ainda em vida, numa entrevista, assumiu que, ao escrever, fazia-o pensando primeiro em Kimbundu, depois em Português. In https://bwevip.com/uma-entrevista-com-uanhega-xitu (Acesso em 03.Jun.2018).

3 Por fim, o idioleto literário de Manuel Rui é caraterizado por uma ficção profundamente marcada por preocupações estéticas de um realismo social, numa linguagem mesclada com expressões e vocábulos tipicamentes angolanos. In sebentadigital.com/wp-content/ uploads/2008/04/manuel_r_monteiro. Ficheiro PDF (Acesso em 03.Jun.2018).
} 
pragmático-semânticas do morfema só na VAP. O que pretendemos referir é que à falta de uma consulta direta ao saber linguístico ou à competência linguística dos falantes, através de um inquérito, e porque o nosso estudo enfoca a análise de um recurso linguístico ocorrente e caraterístico do domínio da linguagem informal, recorremos a enunciados com marcas dialógico-discursivas caraterísticas do discurso oral, a nível da VAP, através do discurso direto de algumas personagens das obras selecionadas.

Assim, constituímos um corpus com dezassete (17) enunciados nos quais selecionamos sete (7) ocorrências do morfema só com o valor de fórmula de cortesia; uma (1) ocorrência com o valor de atenuador; quatro (4) ocorrências com o valor de expressão intensificadora ou expletiva; três (3) ocorrências em que o morfema funciona como constituinte conetivo e duas (2) em que o morfema parece não ter um valor pragmático-semântico preciso, pelo que consideramos ambíguo. Convindo a uma clara e organizada descrição do corpus, o mesmo foi estruturado em cinco pontos, consoante os valores mencionados: fórmula de cortesia, atenuador, intensificador, constituinte conetivo e ambíguo, apresentados exatamente nesta ordem, por um lado. Por outro, porque o contexto, muitas vezes, contribui para a melhor compreensão de determinadas situações 
discursivas, em alguns casos foi necessário apresentar mais do que a frase em que o morfema figura, razão que justifica a extensão de alguns enunciados.

Consideramos que o morfema só, na VAP, é plurifuncional, porque além dos valores gramaticais que the são tradicionalmente atribuídos, os de advérbio e de adjetivo, o mesmo toma outros valores, bastante funcionais, os quais serão agora apresentados e analisados. Assim, os enunciados constitutivos do nosso corpus apresentam o morfema só com esses diferentes valores pragmáticosemânticos. A apresentação e análise do corpus será feita com base nos diferentes valores funcionais do morfema. Em cada subponto são apresentados os enunciados, em primeiro lugar, seguindo-se a análise e, subsequentemente, a caraterização morfossintática.

\section{A) Fórmula de cortesia}

(1a) «Bom dia, minha senhora... É aqui a casa do senhor Felito?»

«Não. Mas posso indicá-la. Passas aquela taberna, na mulembeira, e naquela casa de chapas, vira no lado esquerdo, pergunta aí.»

«Obrigada. - A garota partiu numa mecha. E ao encontrar-se com o Bambula (pobre distribuidor de águas ao domicílio), que empurrava um barril vazio a caminho do chafariz, perguntou: 
"Ó senhor, mi mostra ainda só a casa do senhor Felito?»" (XITO, 1988, p.60)

(1b) "«Ai?! Não viram a Sonsa só?»" (VIEIRA, 2006, p.11)

(1c) “«Xaxão, parece que está tudo em ordem. Olhe-me só pelo Xino e obrigue-o a fazer os deveres todos os dias. ॥" (RUI, 1991, p.145)

(1d) "«Não vais te zangar, não? Desculpa ainda, minha madrinha que me nasceste. Esses teus olhos, haka! Custa a gente sabermos como é teu coração... Te deixo ainda a náua ${ }^{4}$ mais bonita, esta de linho e ponto-crivo, costurei-lhe muitas noites, é de Modas e Bordados. Sim, madrinha, é peça de dentro. Não fica só zangada: está limpa, nunca foi usada, juro! E depois, pensa: o azar, meu azar, é na vida, é no amor... Compreende, minha santa; aceita, minha branca. Tu que sabes tudo no coração das pessoas, vês lá a água limpa, não tem maldade. Aceitas?... É bom ver os teus olhos a rir na tua afilhada... Sou feliz! Vou! Protege só tua devota, minha Sant'Ana Maria, mon'a mundele.»" (VIEIRA, 2006, p.122)

(1e) “Em pé, próximo do quintal, eu e o companheiro vimos sair uma miúda.

«Psiu, vens cá.»

«Ó mano Carlo, que quer?»

«A tua irmã, está em casa?»

4 Roupa interior de mulher. 
«Está lá dentro.»

«Vai chamar. Diga que está aqui o Carlos, mais uma visita.»

«Num quero. Naquele dia me mandaste na loja e disse para me dar chupa-chupa e me intrujaste. Oh, o mano Carlos é muito camuelo ${ }^{5} . »$

«Zinha! Vai só, depressa!...»" (XITO, 1988, p.48)

(1f) "Como o bairro onde eu morava tinha sofrido algumas modificações, Zinha não deu conta da minha casa. Andava bem perto dela. Pensou dirigir-se a uma senhora postada na porta. Mas hesitou. Criou coragem e perguntou:

«Minha senhora, favor só mi mostrar a casa do senhor Felito.»" (XITO, 1988,p.71)

(1g) "«... Xino, baixa só um bocado a televisão.»" (RUI, 1991, p.144)Os enunciados do grupo ora apresentado assumem o morfema só com um valor de fórmula de cortesia. Pragmaticamente, a cortesia linguística refere-se ao uso de estratégias discursivas cuja finalidade é estabelecer ou reestabelecer o equilíbrio das relações sociais, velando pelo respeito do indivíduo enquanto entidade social. Os recursos linguísticos ao serviço da cortesia compreendem as fórmulas de tratamento, as formas de saudação, as formas de apresentação, os agradecimentos, as felicitações,

5 Indivíduo que não gosta de oferecer, vulgo "mão-de-vaca". 
as desculpas, as formas interlocutórias, etc. Os enunciados do grupo em análise têm como principal ato linguístico o diretivo, uma vez que, em termos pragmáticos, o locutor de cada um dos enunciados pretende levar o alocutário à realização futura de uma ação, sendo que em (1a) é a indicação do endereço. Em (1b), há um pedido de informação. Importa destacar, em relação ao mesmo enunciado, que a construção normal (normal no sentido ocorrer com mais frequência) da frase seria "Ai! Não viram só a Sonsa?". Em (1c), regista-se igualmente um pedido, distinto, entretanto, do formulado em (1b) por o locutor não solicitar uma informação, mas um favor. Em (1d), o locutor roga à Santa para que a proteja. Em (1e), o locutor não deixa de formular um pedido. Todavia, o ato ilocutório formulado em (1d) difere dos anteriores, visto que a ocorrência nele do advérbio 'depressa' aproxima-o mais da ordem, o que leva também a inferir que a sua força ilocutória seja diferente. Ou seja, em (1d), o não cumprimento da ação pode ter como consequência a aplicação de uma sanção, se se tiver em conta uma das principais caraterísticas distintivas entre o pedido e a ordem, a relação de poder entre os interlocutores. Atendendo ao fato de o locutor ser um adulto e o interlocutor uma criança apenas, pressupõe a relação dicotómica poder e dever, pelo que a não realização da ação constituiria um ato de desobediência perante o adulto 
(o qual pode ser considerado irmão mais velho, atendendo até às relações sociais entre ambos), o que poderia ser passível de repreensão. A mesma finalidade pragmática reside em (1f) e (1g), quer dizer, estes enunciados também constituem pedidos.

Ora quer o pedido quer a ordem são atos ameaçadores da face negativa (tem a ver com a liberdade de o indivíduo não sofrer imposição) do interlocutor. Tendo isto em conta, por um lado, e sabendo, por outro, que os objetivos pretendidos não visam ao benefício do interlocutor, os locutores recorrem então a fórmulas de cortesia que possam atenuar as ameaças dos atos, ou o aspeto impositivo do mesmo. Neste caso, o morfema só assume o valor de fórmula de cortesia. Em enunciados como estes, na VAP, é frequente a recorrência a este morfema, posto que o mesmo equivale à fórmula de cortesia por favor, o que é testável através do processo de comutação paradigmática:

(1a) «Ó senhor, mi mostra ainda só a casa do senhor Felito?»

«Ó senhor, mi mostra ainda, por favor, a casa do senhor Felito?»

(1b) «Ai?! Não viram a Sonsa só?»

«Ai?! Não viram a Sonsa, por favor?»

(1c) «Xaxão, parece que está tudo em ordem. Olhe-me só pelo Xino e obrigue-o a fazer os deveres todos os dias.» 
«Xaxão, parece que está tudo em ordem. Olhe-me, por favor, pelo Xino e obrigue-o a fazer os deveres todos os dias.»

(1d) ...Protege só tua devota, minha Sant'Ana Maria, mon'a mundele.»

...Protege, por favor, tua devota, minha Sant'Ana Maria, mon'a mundele.»

(1e) «Zinha! Vai só, depressa!...»

«Zinha! Vai, por favor, depressa!...»

(1g) «... Xino, baixa só um bocado a televisão.»

«... Xino, baixa, por favor, um bocado a televisão.»

Estes enunciados confirmam, inegavelmente, que a seleção do morfema só como fórmula de cortesia a nível coloquial na VAP é mais frequente do que a ocorrência da fórmula de cortesia por favor. Esta tendência em substituir a fórmula de cortesia por favor pelo morfema só pode contribuir para a estandardização deste morfema, pois que, afinal, a camada mais fecunda da língua é, conforme Buala ${ }^{6}$ 'o sermo plebeius' ou o falar popular. Os enunciados (1a), (1b) e (1d) constituem atos ilocutórios diretivos de resposta verbal, já que, como propõe Casanova (1989, p.70-71), para a concretização de cada um deles bastará que "o alocutário

6 In www.buala.org/pt/a-ler/o-angoles-uma-maneira-angolana-de-falar-portugues. Acesso em 20.Mai.2017. 
realize uma ação verbal", ao contrário do enunciado (1g). A concretização deste depende da realização de uma ação não-verbal, mas física (diminuir o som da televisão). Neste caso, trata-se de um ato ilocutório diretivo de resposta física. Já a realização dos atos enunciados em (1c), (1e) e (1f) requerem, a nosso ver, ambos os comportamentos, uma vez que 'olhar por uma criança' (o contexto permite deduzir que se trata de uma criança) e 'obrigá-la a fazer os deveres', como pede o locutor em (1c), requererá do alocutário uma orientação que não se limita à verbalização. Aliás, como se sabe, ao orientar, instruir ou educar uma criança, muito mais do que a ação verbal de quem o faz, precisa-se, sobretudo, do seu exemplo em termos de ação. Assim, dizer e fazer são princípios indissociáveis que norteiam a orientação de uma criança. Em (1f), o caso não é muito diferente. Normalmente, quando se endereça alguém, quem o faz não se limita ao uso da linguagem verbal, mas combina esta com a gestual. Ora, ao servir-se da linguagem gestual, praticam-se, na verdade, ações, os gestos. Estes casos, portanto, distinguem-se daqueles, constituindo o que se pode designar, com base no princípio distintivo verbal/não verbal, proposto por Casanova (1989), por atos ilocutórios diretivos de resposta físico-verbal. 
O morfema só enquanto fórmula de cortesia pode coocorrer com a fórmula de cortesia por favor, como em (1f), resultando na intensificação da cortesia. É comum na VAP os pedidos serem formulados com ambas as formas de cortesia "...mostra-me só a casa do senhor Felito, por favor", "Xaxão, olhe-me só pelo Xino e obrigue-o, por favor, a fazer os deveres todos os dias", "Xino, baixa só um bocado a televisão, por favor, etc. Tal como em (1f), em (1a) e em (1b) temos, de igual modo, a combinação de estratégias de atenuação, uma vez que além do morfema só os locutores recorrem à interrogação para a formulação do ato diretivo.

Em termos de caraterísticas funcionais ou sintáticas, o morfema só com o valor de fórmula de cortesia apresenta particularidades comparativamente à fórmula de cortesia por favor. Esta, como vimos, constitui um elemento móvel, podendo figurar em qualquer periferia da frase, e constitui igualmente um elemento sintaticamente autónomo, devendo, por isso, ser destacado do resto da frase, em termos de virgulação. Porém, relativamente à deslocabilidade, o morfema só não se presta a esta propriedade sintática. Os enunciados mostram que a sua posição canónica em relação ao verbo, ou mais propriamente à forma verbal injuntiva, é a enclítica (mas nunca hifenizados). 
(1a) «Ó senhor, mi mostra ainda só a casa do senhor Felito?» (...mostra só...);

(1b) «Ai?! Não viram a Sonsa só?» (...Não viram só...);

(1c) «Xaxão, parece que está tudo em ordem. Olhe-me só pelo Xino e obrigue-o a fazer os deveres todos os dias.» (... Olhe-me só...);

(1d) ...Protege só tua devota, minha Sant'Ana Maria, mon’a mundele.» (...Protege só);

(1e) «Zinha! Vai só, depressa!...» (...Vai só);

(1g) «... Xino, baixa só um bocado a televisão.» (...baixa só).

A tentativa de deslocamento do morfema para a posição proclítica em relação à injunção altera por completo a ideia da frase, como se pode constatar nos exemplos abaixo:

(1b) «Ai! Não só viram a Sonsa?»

(1c) «Zinha! Só vai, depressa!...»

(1d) «... Só Protege tua devota, minha Sant'Ana Maria, mon'a mundele.»

Vê-se que os exemplos (1b) e (1c) ficam sem sentido. Já em (1d), o sentido muda completamente, pois que o morfema perde o valor de fórmula de cortesia, funcionando como advérbio de exclusão, restringindo o sentido do verbo, ou seja, exclui-se a possibilidade de outros devotos serem também protegidos por Sant'Ana Maria, passando somente a locutora a gozar dessa proteção. 
No entanto, apesar de a posição canónica do morfema só ser a pós-verbal, parece existirem exceções. Isto pode ser observado em (1f), " "Minha senhora, favor só mi mostrar a casa do senhor Felito.ı", onde o morfema só figura antes da injunção '...favor só mostrar...'

Em termos flexionais, o morfema só varia quando tem o valor gramatical de adjetivo. Contudo, em nenhum dos enunciados constitutivos do nosso corpus o mesmo é passível de flexão. O que significa, portanto, que apenas o morfema só adverbial se presta a esta plurifuncionalidade, podendo funcionar, conforme o contexto, como fórmula de cortesia, como atenuador, intensificador, constituinte conetivo, etc. Importa sublinhar que na VAP um enunciado como 'Xino, baixa só o som da televisão...' é mais bem recebido pelo interlocutor do que 'Xino, baixa, por favor, o som da televisão...', porque o primeiro dificilmente é tido pelo interlocutor como uma ordem, ao passo que este último pode, dependendo da força ilocutória, soar a ordem. Finalmente, o enunciado (1a) demonstra bem o poder mitigador ou atenuante do morfema só, como fórmula de cortesia. Apesar de, como se pode observar, ocorrer no mesmo exemplo a interjeição vocativa 'ó', a descortesia que o uso dessa interjeição poderia suscitar, por não existir uma estreita relação social entre os interlocutores, não é relevada. 


\section{B) Atenuador}

(2) "«Rico! la-te só dizer para tomares burututu. Tens mau aspeto e às vezes é disso, o fígado.»" (RUI, 1991, p.62)

Neste exemplo, o morfema só tem um valor aproximado ao que o mesmo assume nos enunciados anteriores, mas não apresenta exatamente a mesma função, ou seja, nos enunciados do grupo (1), o locutor socorre-se do morfema com a intensão pragmática de demonstrar cortesia, pelo que o morfema só tem o valor semântico de por favor. Quando o morfema só é tomado como fórmula de cortesia, assume, portanto, um valor dicotómico: atenuação do ato diretivo e conferência de cortesia ao discurso. A assunção de que, neste exemplo, o morfema toma um valor aproximado ao valor que o mesmo tem nos enunciados anteriores é precisamente por o morfema, quer naquele grupo quer neste, funcionar como atenuador. Não há certamente dúvida de que em (2) temos um ato diretivo cujo objetivo ilocutório remete propriamente para o conselho ou sugestão. Tratando, pois, de um conselho ou de uma sugestão, "o locutor pode «interessar-se» mais ou menos vivamente pelo cumprimento da sugestão, tornando-a de certa forma personalizada ou despersonalizada" (CASANOVA, 1989, p.434), o que não se verifica no enunciado em análise, visto que a direção de interesse 
não visa a beneficiar e satisfazer o locutor, mas a mesma é favorável ao alocutário. O interesse é, indubitavelmente, do alocutário, visto que é em benefício do seu estado de saúde que se lhe dirige o ato. Não pretendemos com isto assumir que as sugestões ou os conselhos constituem atos ilocutórios diretivos que não seguem o princípio da cortesia. No entanto, a ocorrência do morfema só em (2) não objetiva propriamente a demonstração da cortesia, senão minimizar o aspeto desagradável que o proferimento relativo ao estado de saúde do alocutário poderia provocar. Está-se diante de uma estratégia de atenuação cuja finalidade é a autoproteção do locutor (BRIZ, 2014, p.106-108), uma vez que ele alude ao 'mau aspeto' do seu interlocutor.

É, enfim, o que sucede em construções como 'Ela é feiinha, apesar de os pais serem bonitos.', cuja atenuação não está propriamente para a cortesia, mas sim para suavizar o efeito desconfortante veiculado pelo adjetivo 'feia'. No enunciado em análise temos, por um lado, a atenuação pragmática, pela modificação do verbo (socorrendo-se da conjugação perifrástica 'ia-te pedir', com o verbo auxiliar desatualizado, isto no imperfeito), por outro, a atenuação semânticopragmática, pelo fato de o morfema só atenuar o conteúdo proposicional na sua totalidade, embora o mesmo tipo de atenuação possa abranger só parte do conteúdo. 
Em termos funcionais, o morfema só neste exemplo assume as mesmas caraterísticas em relação às assumidas quando o mesmo funciona como fórmula de cortesia. Como vimos, enquanto fórmula de cortesia, o morfema só funciona com frequência em adjacência imediata ao verbo indicador da injunção, posição igualmente tomada em 2. Mas por se tratar, neste caso, de conjugação perifrástica, o morfema figura depois do verbo auxiliar 'ir', 'ia', portanto. Se o mesmo ocorresse depois do verbo principal da primeira oração, 'dizer', ou depois do verbo injuntivo, 'tomar', haveria uma ligeira mudança de sentido, uma vez que ou o verbo 'dizer' ou o 'tomar' passariam a ser o foco e, como tal, restringir-seia o sentido destes, passando a significar que o interlocutor deveria tomar só e unicamente burututu.

\section{C) Intensificador ou expressão expletiva}

(3a) "Beto e Xico voltaram para junto do cesto e deixaramse ficar ali a mirar outra vez galinha Cabíri. O bicho tinha-se assustado com todo o barulho das macas com sô Zé, mas, agora, sentindo o ventinho fresco a coçar-lhe debaixo das asas e das penas, aproveitou o silêncio e começou cantar.

«Sente, Beto! - sussurrou-Ihe Xico. - Sente só a cantiga dela!»" (VIEIRA, 2004, p.88) 
(3b) “"Xé, Felito! Não está ouvir? Vou contar-te na mana Bia, espera só.»" (XITO, 1988, p.44)

(3c) "«Pois é! Quando sabem: porquê, porcauso, sou boa e tudo mais, parece é papagaio! Quando não sabem: ai, porquê, porcauso, você é que inventou à toa! Deixem só»!" (VIEIRA, 2006, p.136)

(3d) “«Esse Kanini?!... Língua dele, pop'las! Deviam de ouvir só as conversas quando Ihe comprou, lá no sítio da cacimba do Silvestre!...»" (VIEIRA, 2006, p.86)

Entre as várias funções desempenhadas pelos advérbios a intensificação é uma delas. Os advérbios de intensidade muito, mais e os chamados advérbios de modo, os sufixais, derivados em -mente são os que mais concorrem para esse processo. No entanto, estes advérbios remetem para a intensificação ou modificação gradual de, por exemplo, um verbo ('Trabalhei muito' durante a última noite), um adjetivo (Sinto-me 'mais folgado' agora...), ou mesmo de um outro advérbio (Trabalhos desta natureza nunca estão 'perfeitamente bem'.). Ora, a intensificação presente nos enunciados acima não tem que ver com a intensificação gradual, mas com a intensificação expletiva. A intensificação expletiva (também conhecida como realce) consiste no simples reforço expressivo daquilo que se diz. 
Vilela (1999, p.262) designa por 'partículas gradativas ou seriativas' as expressões que enfatizam ou referem grandezas, pela delimitação ou exclusão, e inclui nelas os advérbios de exclusão. Como se sabe, quando uma expressão desempenha funções meramente expletivas, a sua ocorrência no enunciado é dispensável, podendo, por isso, ser elidida. Em todos os exemplos que constituem o grupo (3) verifica-se que a destituição do morfema não altera o conteúdo semântico das frases:

(3a) «Sente, Beto! (...) Sente a cantiga dela!»

(3b) «Xé, Felito! Não está ouvir? Vou contar-te na mana Bia, espera.»

(3c) «Pois é! Quando sabem: porquê, porcauso, sou boa e tudo mais, parece é papagaio! Quando não sabem: ai, porquê, porcauso, você é que inventou à toa! Deixem»!

(3d) «Esse Kanini?!... Língua dele, pop'las! Deviam de ouvir as conversas quando lhe comprou, lá no sítio da cacimba do Silvestre!...»

Apesar de as expressões intensificadoras ou enfáticas serem elementos sintático-semanticamente dispensáveis à estrutura frasal, em (3b), porém, o morfema só tem uma carga semântico-psicológica pertinente. A oração 'espera só' funciona como um ato perlocutório cujo efeito é bastante 
persuasivo ou até mesmo ameaçador, uma vez que a oração, 'espera só', a qual pode ser parafraseável como 'certamente', 'hás de ver', 'podes crer', etc. acentua a decisão do locutor em contar o sucedido. Em (3b), a intensificação tem, portanto, uma função semântico-pragmática, uma vez que o morfema modifica o conteúdo proposicional, e tem um determinado efeito perlocutivo. Em termos de caraterísticas funcionais, neste grupo, à semelhança dos casos precedentes, o morfema só tem como foco o verbo, ou seja, funciona como um modificador do grupo verbal ('sente só', 'espera só', 'deixem só', 'deviam de ouvir só'), não sendo suscetível de mobilidade ou de o mesmo funcionar na posição pré-verbal ('só sente', 'só espera', 'só deixem', 'só deviam de ouvir.'), pois que a deslocação para a posição proclítica modificaria o seu papel de expressão intensificadora, funcionando, mais uma vez, como advérbio de exclusão. Para concluir, importa sublinhar que os núcleos 'deviam de ouvir só', 'espera só', etc. não têm o semantismo de, por exemplo, 'vocês deviam ouvir unicamente e calar-se', ou 'não faças mais nada senão esperar', o que equivale dizer que nos exemplos analisados o morfema só não tem funções excludentes.

\section{D) Constituinte conetivo}

(4a) "E sô Januário, dono de loja e fazenda de café, de passear a mulata, arreada e pintada, em domingo de 
Marginal; e arreguenhando polícia se «esse miserável carpinteiro cabo-verdiano» passasse, só que fosse, na frente da casa..." (VIEIRA, 2006, p.11)

(4b) "«Só se a gente não nasceu na mesma barriga.»" (XITO, 1988, p.119)

(4c) “"Então, arranjaste?»

«Arranjei. O mesmo. Falou sim, podemos entregar. Só que fica mais longe, não quer lá em casa. Qu'até meia-noite o homem espera. É o Zeca, não sei se Ihe conheces»..." (VIEIRA, 2004, p.63)

O morfema só funciona como constituinte conetivo. Como se sabe, as conjunções e as preposições são os recursos de que a língua dispõe para desempenhar funções conetivas (VILELA, 1999, p.249, 253). Mas, na VAP, é comum empregar-se o morfema só como constituinte conetivo, tal como se apresenta nos enunciados acima. Em (4a) '... só que...' equivale aos concessivos 'ainda que', 'nem que'. Pode também ter o significado de 'pelo menos': “...se «esse miserável carpinteiro cabo-verdiano» passasse, ainda/nem que fosse, na frente da casa..."; em (4b), 'só se', funciona como conetor subordinativo condicional: 'a menos que', 'a não ser que': " "A menos que/a não ser que a gente não *nasceu na mesma barriga.»". Em (4c), finalmente, 'só que' 
tem um valor adversativo: 'mas', 'no entanto'... «Arranjei. O mesmo. Falou sim, podemos entregar. Mas/no entanto fica mais longe, não quer lá em casa. Qu'até meia-noite o homem espera. É o Zeca, não sei se Ihe conheces»...".

Ocorrendo com a função acima descrita, o morfema só opera sempre em adjacência a um elemento com a função de conetor, constituindo com o mesmo uma locução conjuncional, na qual o morfema só funciona como primeiro constituinte, não suscetível de flexão, dada também a invariabilidade dos instrumentos linguísticos que desempenham funções de ligação.

\section{E) Valores ambíguos}

Vimos, até então, ocorrências do morfema só como fórmula de cortesia, atenuador, intensificador e constituinte conetivo. Tentemos, por último, analisar o valor do mesmo morfema nos dois enunciados que se seguem:

(5a) "Inácia ria, torcida com cócegas, a cara de raivado do Garrido Fernandes. E quando o rapaz levantou-se devagar para adiantar arrancar com a perna aleijada, feito pouco, triste e envergonhado, Inácia chamou-lhe manso, com todo o açúcar preto da voz dela:

«Gagá! Não me deixa só no escuro...» É que o escuro tinha descido já. As luzes começavam piscar em todos os lados, 
na quitanda já tinha barulho de homens a gastar o dinheiro no vinho, voltando do serviço. Garrido parou, baralhado, não sabia se ficava, se ia embora; se calhar era só para adiantar fazer mais pouco que lhe chamava, a voz era de mentira, aquele Gagá não queria dizer. Mas, devagar, veio sentar-se mais perto dela, pediu:

«Primeiro, se você quer eu fico, enxota o fidamãe do Jacó!»" (VIEIRA, 2004,p.56)

(5b) " "Quiuáia”, essa gaja é que é! Quitata de dormir com os gajos no capim! Rosqueira! Te arranjaram até uma mulumba, sua sonsa de merda! Cadela d'arrastar a bunda no chão! Os cães não te querem!... Não pendura só sua roupa na corda, jacaréua!»" (VIEIRA, 2006, p.103-104)

Em (5a), trata-se, evidentemente, de um pedido, se atendermos às caraterísticas da frase, sendo o uso do verbo no modo imperativo ${ }^{8}$ a marca mais evidente. Até aqui não há dúvida de que a mesma constitui um ato diretivo. Sendo assim, é passível atribuir-se ao morfema só o valor de fórmula de cortesia. Contudo, há a possibilidade de se lhe atribuir outro valor semântico. Se, por um lado, pensarmos que o locutor, neste caso a locutora, se socorre do morfema

\footnotetext{
7 Meretriz.

8 Trata-se, na verdade, do modo indicativo, para sermos mais corretos. Mas o contexto permite atribuir ao verbo o valor imperativo. O mesmo ocorre com a forma verbal em (5b). 0 uso do indicativo na formação do imperativo negativo é, aliás, uma das caraterísticas da VAP.
} 
só com o preciso objetivo de expressar a necessidade de o alocutário lhe prestar um favor, o de não a deixar no escuro, porquanto, como vimos, a direção de interesses, quando se formula um pedido, tem como beneficiário o locutor (CASANOVA, I.), então é certo que o morfema funciona como fórmula de cortesia, tendo o valor semântico de por favor. Servindo-nos, neste caso, do princípio ou do critério semântico da comutação nas relações sintagmáticas (FABRE, 1990, p.196), poderemos, portanto, conceber assim a frase: «Gagá! Não me deixa, por favor, no escuro...». Por outro lado, porém, a mesma frase favorece a atribuição de outro valor semântico ao morfema. Ela continuará perfeitamente compreensível se, por exemplo, comutarmos o morfema só pelo sintagma sozinha. Ora, diante disto, parece não haver objeção para se atribuir ao morfema o valor adjetival. Há, ademais, a possibilidade de a frase ocorrer sem o morfema só, e não haver, mesmo assim, alteração do seu conteúdo semântico: "Gagá! Não me deixa no escuro...». Neste caso, podemos, enfim, conceber o morfema só como expressão intensificadora. Quanto às caraterísticas funcionais, importa apenas sublinhar, para não sermos prolixos, que o mesmo seria flexionável em número, caso se lhe fosse atribuído o valor adjetival, pluralizando a frase: «Gagá! Não nos deixa sós no escuro...». 
Mais complexo de analisar é o valor do morfema só em (5b): “...Não pendura só sua roupa na corda, jacaréua!”. O valor imperativo do verbo 'pendurar' obvia o ato de ordem, ou, se quisermos, o ato diretivo, especificamente o aviso. Tratandose, pois, de um ato diretivo, a ocorrência do morfema só induz a atribuir-lhe o valor de fórmula de cortesia e, consequentemente de atenuador. Todavia, é paradoxal falarse em cortesia num contexto como este, tendo em conta que i) a cortesia consiste também na adoção de comportamentos culturais e socialmente aceitos (HILGERT, 2008, p.134) e que ii) uma das suas funções é exatamente a demonstração de simpatia e de respeito ao interlocutor, durante a interação conversacional. No contexto em análise, ocorre, por um lado, o desrespeito a um dos princípios de cortesia desenvolvido por Leech (1997, p.209), a chamada máxima da simpatia, que consiste no seguinte: "minimizar la antipatía entre uno mismo y el otro y maximizar la simpatía entre uno mismo y el outro". A atitude do locutor aponta para um ato descortês ou conflitivo, o qual vai de encontro às boas relações sociais entre os interlocutores, tais como a acusação, a maledicência (ato que ameaça a face positiva do interlocutor), etc. Não se observa, por outro lado, uma das máximas conversacionais de Grice, a da qualidade, uma vez que é falsa e inadequada a alusão à metáfora 'jacaréua'. Também pode ser verdade pensar que a ocorrência do morfema só tem por objetivo 
intensificar o aviso, funcionando, por conseguinte, como um elemento expletivo. $O$ desrespeito a estes princípios de cortesia suscitam dúvidas quanto ao funcionamento do morfema só como fórmula de cortesia. Outrossim, a possibilidade de o morfema funcionar como expressão intensificadora dificulta ainda mais a atribuição de um valor funcional exato ao morfema no contexto em questão. Daí considerarmos ambíguo o valor funcional do morfema só nos dois últimos casos.

Poderíamos citar outras ocorrências em que o morfema só pode ter um valor ambíguo, como é o caso do exemplo a seguir, embora o mesmo não faça parte do corpus:

"Traz só os livros que estão sobre a cama".

Neste caso, usa-se o morfema só como fórmula de cortesia, ou tem o mesmo uma função restritiva, com o valor gramatical de advérbio de exclusão, cujo sentido poderia ser parafraseável por 'quero que tragas os livros que estão sobre a cama, mas não os que se encontram sobre a secretária', por exemplo? Tendo consciência de que o funcionamento do morfema só na VAP constitui um tema ainda em aberto, deixamos esta e outras questões que eventualmente possam surgir para estudos posteriores. 


\section{CONCLUSÃO}

A análise descritiva do morfema só permitiu-nos comprovar a plurifuncionalidade pragmático-semântica do mesmo morfema. Foi possível perceber que o equivalente do morfema só em Kimdundu é, muitas vezes, associado aos atos diretivos e, consequentemente, à cortesia. Haja vista as interferências do Kimbundu na VAP, por um lado, e porque a cortesia é uma instituição social e cultural, por outro, o morfema só passou a ser usado naquela variedade africana do português com o mesmo valor pragmáticosemântico atribuído ao seu equivalente Kimbundu, ou seja, o uso do morfema só associado aos atos diretivos, na VAP, é reflexo de como se operacionaliza a cortesia em Kimbundu. Ainda no que diz respeito à operacionalização do morfema só na VAP, conclui-se que o mesmo não só funciona como advérbio, adjetivo ou fórmula de cortesia, mas também como expressão intensificadora e constituinte conetivo, além de poder assumir outros valores semânticos.

\section{REFERÊNCIAS}

BRIZ GÓMEZ, A. (2014). "La atenuación lingüistica. Esbozo de una propuesta teórico-metodológica para su análisis". In: SEARA, I. (Org.). Cortesia: olhares e (re)invenções. Lisboa: Chiado Editora, p.83-144. CASANOVA, Isabel (1989). Actos ilocutórios directivos: a força do poder ou o poder da persuasão. Lisboa: Faculdade de Letras da Universidade de Lisboa. 
BAYLON, Christian; FABRE, Paul (1990). Iniciação à linguística. Coimbra: Almedina.

HILGERT, J. G. (2008). “A cortesia no monitoramento de problemas de compreensão". In: PRETI, D. (Org.). Cortesia verbal. São Paulo: Humanitas. p.125-156.

LARANJEIRA, Pires (1995). Literaturas africanas de expressão portuguesa. Lisboa: Universidade Aberta.

LEECH, Geoffrey (1997 [1983]). Princípios de pragmática. Rioja: Universidad de la Rioja, Servicio de Publicaciones.

RUI, Manuel (1991). Crónica de um mujimbo. Lisboa: Edições Cotovia.

VIEIRA, José. Luandino (2004). Luuanda. Luanda: Editorial Nzila. Lisboa: Editorial Caminho. (2006). Velhas Estórias. Luanda: Editorial Nzila. Lisboa: Editorial Caminho.

VILELA, Mário. (1999). Gramática da língua portuguesa.2.ed. Coimbra: Almedina.

XITO, Uanhenga (2014). Entrevista In https://bwevip.com/uma-entrevistacom-uanhega-xitu. Acesso em 12.Fev.2018 (1988). Manana. Rio Tinto: Edições Asa.

Paulo Osório é Licenciado em Humanidades - Português, Latim e Grego, pela Faculdade de Letras da Universidade Católica Portuguesa (1994); Mestre em Linguística Portuguesa, pela Faculdade de Letras da Universidade de Coimbra (1998); Doutor em Letras (Linguística Portuguesa), pela Universidade da Beira Interior (2002); Pós-Doutor em Letras (Estudos da Linguagem), pela PUC-Rio (2006) e obteve o título de Agregado, em 2009, no ramo de Letras (Linguística Portuguesa), pela Universidade da Beira Interior. Desenvolve investigação em Linguística Histórica, História da Língua Portuguesa e em Linguística Aplicada. Atualmente, é Professor Associado com Agregação da Faculdade de Artes e Letras da Universidade da Beira Interior (Covilhã, Portugal), onde tem desempenhado variadíssimos cargos de gestão académica, tendo presidido, entre 2013 a 2017, ao Departamento de Letras. 
Kimavuidi Anacleto José Ferreira é licenciado em Ensino do Português, pelo Instituto Superior de Ciências da Educação (ISCED) de Luanda (2013) e Mestre em Estudos Lusófonos, com uma dissertação na área da Linguística, pela Universidade da Beira Interior, Portugal (2018). As suas áreas de investigação centram-se na Linguística Africana, na Pragmática e nos Atos Discursivos. Tem, ao nível da docência, colaborado, entre outras instituições, com o Instituto Superior de Ciências da Educação (ISCED) de Luanda, com o Instituo de Línguas (IL), o Instituto Superior Técnico Militar (ISTM) e o Instituto Superior Politécnico Inocêncio Nanga (ISPIN).

Recebido em 03 de julho de 2018. Aprovado em 30 de agosto de 2018. 